\title{
Highly Selective Fluorescent Recognition of Glutathione by Using a Water Soluble Binaphthyl Aldehyde
}

\author{
Wei Chen, Xuedan Wu and Lin Pu* \\ Department of Chemistry, University of Virginia, Charlottesville, Virginia 22904-4319, U.S.A. \\ Email Address: 1p6n@virginia.edu
}

\begin{abstract}
A water soluble binaphthyl-based aldehyde was designed and synthesized. This compound in combination with $\mathrm{Zn}(\mathrm{OAc})_{2}$ is found to exhibit greatly enhanced fluorescence in the presence of GSH in aqueous solution $(\mathrm{pH}=7.5$ ) but give little or no fluorescence enhancement in the presence of cysteine, homocysteine and other amino acids. This remarkable selectivity makes this probe potentially useful for the analysis of the biologically important GSH.
\end{abstract}

\section{Keywords: Fluorescence sensor Glutathione Zinc BINOL Aldehyde}

Intracellular thiols including glutathione (GSH), cysteine (Cys) and homocysteine (Hcy) play important roles in physiological and pathological processes, and extensive studies have been conducted to detect these molecule. ${ }^{1-3}$ Utilizing the nucleophilic reactions of the thiols has led to the development of a number of fluorescent sensor for GSH, Cys and Hcy. ${ }^{1-3}$ However, to distinguish these biologically significant thiols from each other has become a challenge. Although several reports have appeared for

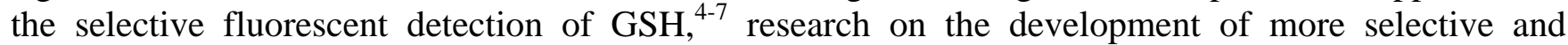
efficient fluorescent sensors continues.

In 2014, we discovered that the 1,1'-bi-2-naphthol (BINOL)-based aldehyde 1 in combination with $\mathrm{Zn}^{2+}$ exhibits enantioselective fluorescent enhancement in the presence of chiral amines in methanol solution. ${ }^{8}$ In order to explore the application of the BINOL-based molecules for the fluorescent detection of biologically important molecules in water solution, we have synthesized a water soluble analog of this compound. Herein, we report that a highly selective fluorescent sensor for GSH by using the BINOL-based compound in aqueous solution.

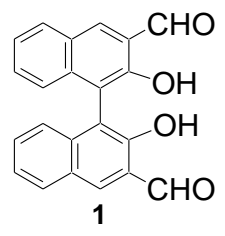

In order to make the BINOL-based aldehyde soluble in water, we have incorporated a quaternary ammonium cation as shown in Scheme 1. Compound 2 was prepared from $(S)$-BINOL according to the literature. ${ }^{9}$ Treatment of 2 sequentially with 1,3-dibromopropane and morphline under basic conditions gave 3. Ortho-metalation of $\mathbf{3}$ with ${ }^{\mathrm{n}} \mathrm{BuLi}$ followed by addition of DMF and acidic deprotection gave the BINOL-aldehyde compound $\mathbf{4}$. Reaction of $\mathbf{4}$ with MeI gave the desired quaternary ammonium salt 5 which is found to be soluble in aqueous solution. ${ }^{10}$ In DMSO- $d_{6}$ solution, compound 5 gave two ${ }^{1} \mathrm{H}$ NMR signals at $\delta 10.36(\mathrm{~s}, 1 \mathrm{H})$ and $10.15(\mathrm{~s}, 1 \mathrm{H})$ which are assigned to the signals of the aldehyde and hydroxyl protons respectively. In $\mathrm{D}_{2} \mathrm{O}$ solution, the aldehyde proton signal was observed at $\delta 10.24$ while the phenol proton disappeared by H/D exchange. 
Scheme 1. Synthesis of the water soluble binaphthyl aldehyde 5.

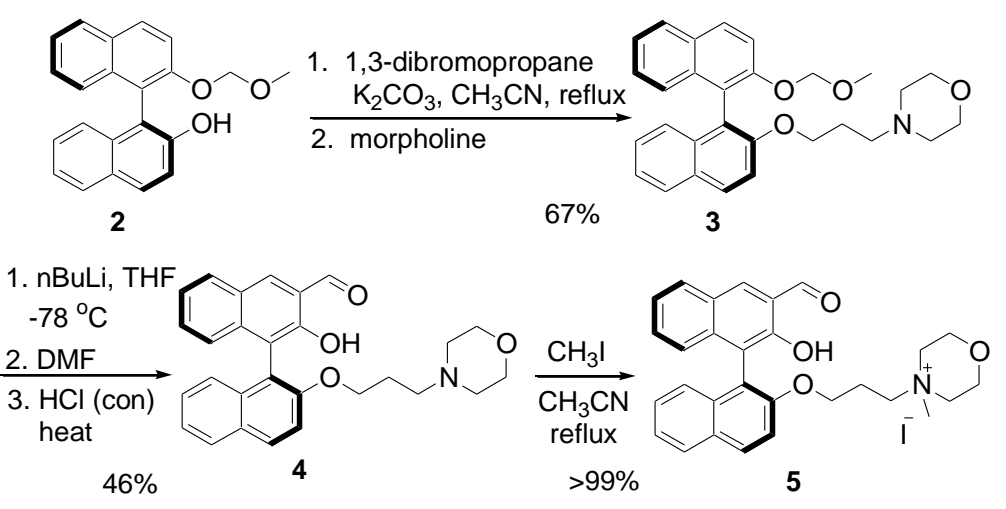

We have examined the fluorescence response of 5 in combination with $\mathrm{Zn}(\mathrm{OAc})_{2}$ (1 equiv) toward GSH, Cys, Hcy, GSSG (the disulfide of GSH), and various natural amino acids in HEPES buffer solution $(\mathrm{pH}=7.5) .{ }^{11}$ As shown in Figure 1 , when the mixture of $5\left(2.0 \times 10^{-5} \mathrm{M}\right)+\mathrm{Zn}(\mathrm{OAc})_{2}(1$ equiv) was treated with these analytes, GSH gave large fluorescence enhancement at $\lambda=560 \mathrm{~nm}$. All the other analytes gave much smaller or none fluorescence enhancement (Figure 1).

Figure 1. Fluorescence spectra of $5\left(2.0 \times 10^{-5} \mathrm{M}\right)$ and $\mathrm{Zn}(\mathrm{OAc})_{2}(1.0$ equiv) in HEPES buffer solution $(\mathrm{pH}=7.5)$ after treated with various amino acids $\left(2.0\right.$ equiv) for $4 \mathrm{~h}$ at room temperature $\left(\lambda_{\mathrm{exc}}=430\right.$ $\mathrm{nm}$;slit: $5 / 5 \mathrm{~nm})$.

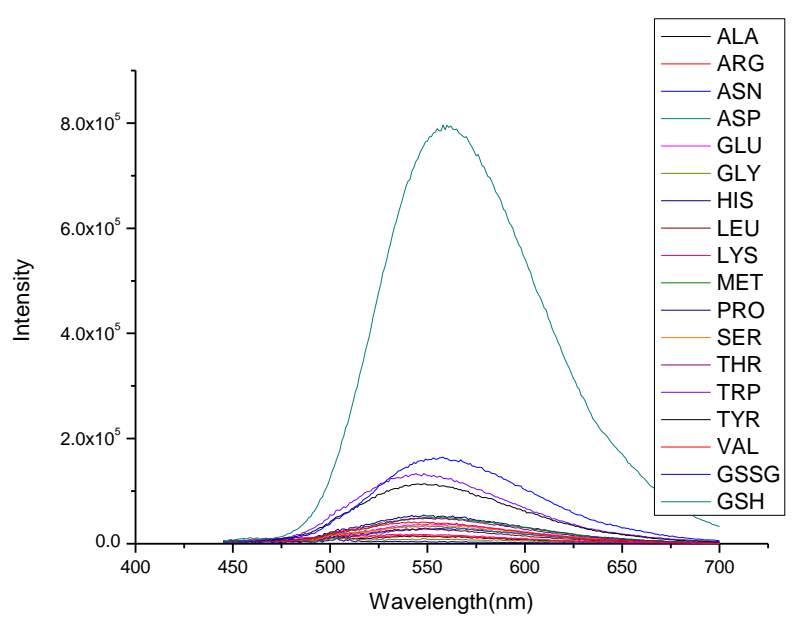

(a)

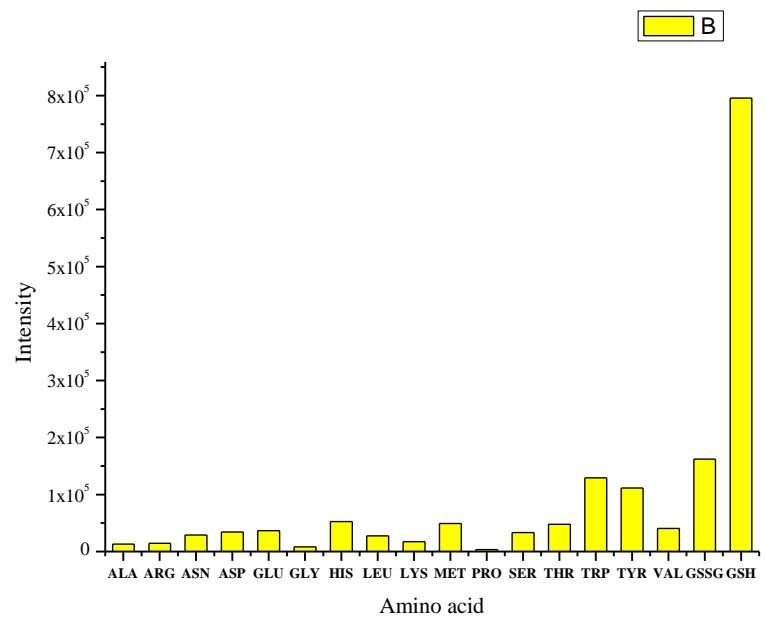

(b)

We have compared the fluorescence responses of 5 toward GSH, Cys and Hcy at various concentrations of the substrates. As shown in Figure 2a, GSH caused much greater fluorescence enhancement than Cys and Hcy. The fluorescence enhancement of $5+\mathrm{Zn}(\mathrm{OAc})_{2}$ in the presence of GSH reached saturation when the concentration of GSH is $>4$ equiv of the sensor. The fluorescence responses of $\mathbf{5}$ toward the amino acids versus the reaction time are given in Figure $2 \mathrm{~b}$. It shows that the fluorescence response of 5 toward GSH became stable after $4 \mathrm{~h}$.

Figure 2. Fluorescence responses of $5\left(2.0 \times 10^{-5} \mathrm{M}\right)$ and $\mathrm{Zn}(\mathrm{OAc})_{2}(1.0$ equiv) in HEPES buffer solution $(\mathrm{pH}=7.5)$ at $\lambda=560 \mathrm{~nm}$ (a) after treated with GSH, Cys and Hcy at various concentrations for $4 \mathrm{~h}$ at room temperature, and (b) after treated with 2.0 equiv of GSH, Cys or Hcy at various reaction time. $\left(\lambda_{\text {exc }}=430 \mathrm{~nm}\right.$;slit: $5 / 5 \mathrm{~nm}$. The error bars were obtained with three independent measurements) 


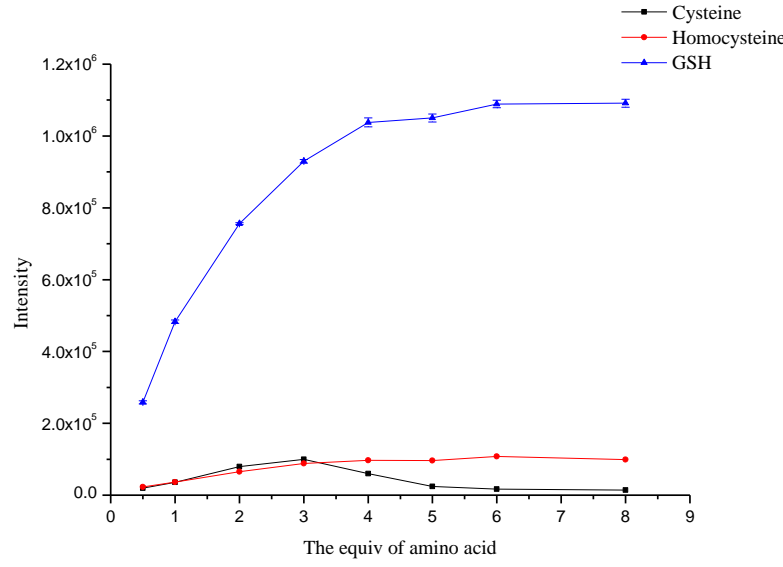

(a)

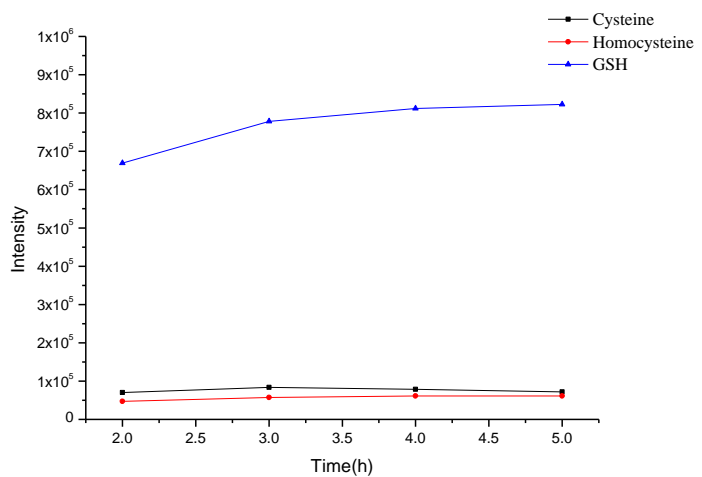

(b)

We also compared the fluorescence response of 5 toward GSH in air versus that under nitrogen, and little difference was observed when the reactions were conducted in HEPES $(\mathrm{pH}=7.5)$ at room temperature for $4 \mathrm{~h}$ (see page S9 in SI). Although it is known that GSH in aqueous solution at higher $\mathrm{pH}$ can be oxidized in air over time, ${ }^{12}$ it does not influence the fluorescence measurement for our probe.

We have also studied the fluorescence response of $\mathbf{5}+\mathrm{Zn}(\mathrm{OAc})_{2}$ (1 equiv) toward GSH in the presence of other 21 amino acids as well as GSSG in HEPES buffer solution ( $\mathrm{pH}=7.5)$. As shown in Figure 3, when a mixture of $5\left(2.0 \times 10^{-5} \mathrm{M}\right)+\mathrm{Zn}(\mathrm{OAc})_{2}$ (1 equiv) was treated with GSH and another substrate, the fluorescence enhancement at $\lambda=560 \mathrm{~nm}$ was mostly maintained except in a few cases. For these cases including Hcy, Cys, ASP, His and GSSG, the maximum tolerated concentrations of these substrates in this GSH sensing system are shown in Figure 3. Overall, the fluorescence intensity changes are below $5 \%$ which demonstrate 5 as a reliable and selective sensor for GSH. We have also found that the detection limit of this method for GSH is $1.72 \times 10^{-6} \mathrm{M}$ (see page S8 in SI), indicating a high sensitivity.

Figure 3. Fluorescence intensity of $5\left(2.0 \times 10^{-5} \mathrm{M}\right)$ and $\mathrm{Zn}(\mathrm{OAc})_{2}$ (1.0 equiv) in HEPES buffer solution ( $\mathrm{pH}=7.5)$ at $\lambda=560 \mathrm{~nm}$ after treated with $\mathrm{GSH}(4.0$ equiv) and another amino acid (4.0 equiv unless the maximum tolerated concentration is indicated) for $4 \mathrm{~h}$ at room temperature $\left(\lambda_{\text {exc }}=430 \mathrm{~nm}\right.$; slit: $5 / 5 \mathrm{~nm}$.)

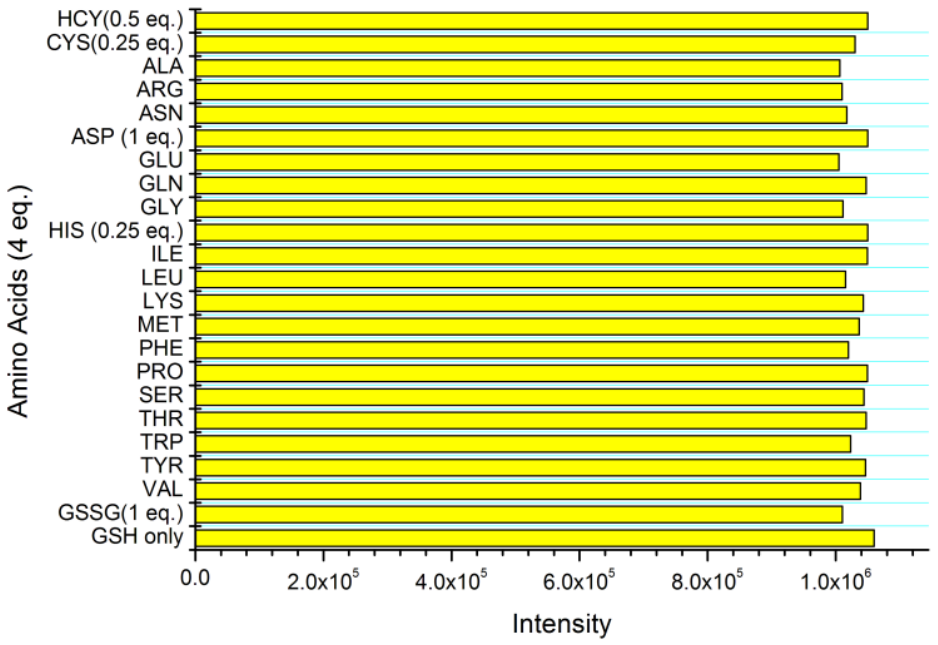


We have studied the NMR spectrum for a mixture of 5 with $\mathrm{Zn}(\mathrm{OAc})_{2}$ and GSH (1:1:2) in $\mathrm{D}_{2} \mathrm{O}$ and observed no significant reaction. However, when the $\mathrm{pH}$ of the solution was increased with the addition of $\mathrm{K}_{2} \mathrm{CO}_{3}$ (2 equiv), most of the organic compounds precipitated out with greatly diminished NMR signals. That is, the solubility of the product is too low to be detected by ${ }^{1} \mathrm{H}$ NMR analysis (see page $\mathrm{S} 11$ in $\mathrm{SI}$ ).

We have also obtained the mass spectrum for the reaction solution of 5 with 1 equiv $\mathrm{Zn}(\mathrm{OAc})_{2}$ and 2 equiv GSH in HEPES ( $\mathrm{pH}=7.5$ ) which gives a signal at $\mathrm{m} / \mathrm{z}=1784.2$ (see page $\mathrm{S} 12$ in $\mathrm{SI}$ ). A oligomeric structure 6 could be used to account for this signal. ${ }^{13}$ GPC analysis of the reaction mixture showed $\mathrm{M}_{\mathrm{w}}=5000$ and $\mathrm{M}_{\mathrm{n}}=2700(\mathrm{PDI}=1.8$ ) relative to polystyrene standards. Therefore, we propose that the decreased solubility for the reaction product of 5 with $\mathrm{Zn}(\mathrm{OAc})_{2}$ and $\mathrm{GSH}$ at $\mathrm{pH}=7.5$ or higher could be attributed to the formation of oligomers such as $\mathbf{6}$ or its aggregates. The greatly increased fluorescence could be due to the aggregation enhanced emission. ${ }^{14}$ Cys, Hcy and other amino acids cannot generate such oligomeric structure under the same conditions and thus give little or non fluorescence enhancement.

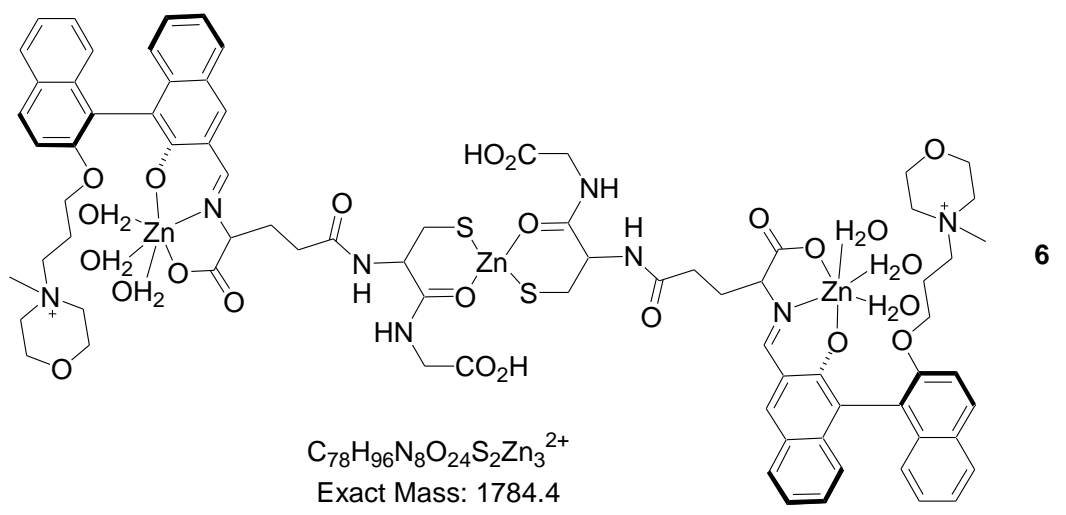

In summary, we have synthesized a BINOL-based water soluble aldehyde by incorporation of a quaternary ammonium unit. This compound in combination with $\mathrm{Zn}(\mathrm{OAc})_{2}$ is found to exhibit greatly enhanced fluorescence in the presence of GSH. This probe shows remarkable selectivity over Cys, Hcy and other amino acids. It is potentially useful for the analysis of this biologically important species.

Acknowledgment. Partial supports of this work from the US National Science Foundation (CHE1565627) is gratefully acknowledged.

\section{References and Notes:}

1. Chen, X.; Zhou, Y.; Peng, X.; Yoon, J. Chem. Soc. Rev. 2010, 39, 2120-2135;

2. Jung, H.; Chen, J.; Yoon, J.; Kim, J. Chem. Soc. Rev. 2013, 42, 6019-6031;

3. Yin, C.; Huo, F.; Zhang, J.; Martinez-Máñez, R.; Yang, Y.; Lv, H.; Li, S. Chem. Soc. Rev. 2013, 42, 6032-6059;

4. Niu, L.; Guan, Y.; Chen, Y.; Wu, L.; Tung, C.; Yang, Q. J. Am. Chem. Soc. 2012, 134, 18928-18931.

5. Guo, Y.; Yang, X.; Hakuna, L.; Barve, A.; Escobedo, J. O.; Lowry, M.; Strongin, R. M. Sensors 2012, 12, 5940-5950.

6. (a) Yin, J.; Kwon, Y.; Kim, D.; Lee, D.; Kim, G.; Hu, Y.; Ryu, J.; Yoon, J. J. Am. Chem. Soc. 2014, 136, 5351-5358.

(b) Lim, S.; Hong, K.; Kim, D.; Kwon, H.; Kim, H. J. Am. Chem. Soc. 2014, 136, 7018-7025.

7. (a) Wang, F.; Zhou, L.; Zhao, C.; Wang, R.; Fei, Q.; Luo, S.; Guo, Z.; Tian, H.; Zhu, W. Chem. Sci. 2015, 6, 25842589. (b) Chen, J.; Jiang, X.; Carroll, S. L.; Huang, J.; Wang, J. Org. Lett. 2015, 17, 5978-5981.

8. Huang, Z.; Yu, S.; Wen, K.; Yu, X.; Pu, L. Chem. Sci. 2014, 5, 3457-3462.

9. Kiyooka, S.; Tada, M.; Kan, S.; Fujio, M. Bull. Chem. Soc. Jpn. 1996, 69, 2595-2601.

10. Characterization data of 5: yellow solid. mp $152-153{ }^{\circ} \mathrm{C}$. ${ }^{1} \mathrm{H}$ NMR $\left(600 \mathrm{MHz}, \mathrm{DMSO}-d_{6}\right) \delta 10.36(\mathrm{~s}, 1 \mathrm{H}), 10.15(\mathrm{~s}$, $1 \mathrm{H}), 8.66(\mathrm{~s}, 1 \mathrm{H}), 8.20-8.08(\mathrm{~m}, 2 \mathrm{H}), 7.99(\mathrm{~d}, 1 \mathrm{H}, \mathrm{J}=7.8 \mathrm{~Hz}), 7.65(\mathrm{~d}, 1 \mathrm{H}, \mathrm{J}=9.0 \mathrm{~Hz}), 7.48-7.40(\mathrm{~m}, 2 \mathrm{H}), 7.38(\mathrm{t}, 1 \mathrm{H}, \mathrm{J}$ $=7.2 \mathrm{~Hz}), 7.29(\mathrm{t}, 1 \mathrm{H}, \mathrm{J}=7.2 \mathrm{~Hz}), 7.01(\mathrm{~d}, 1 \mathrm{H}, \mathrm{J}=8.4 \mathrm{~Hz}), 6.99-6.93(\mathrm{~m}, 1 \mathrm{H}), 4.23-4.14(\mathrm{~m}, 1 \mathrm{H}), 4.13-4.06(\mathrm{~m}, 1 \mathrm{H})$, 3.82-3.70 (m, 2H), $3.57(\mathrm{~d}, 1 \mathrm{H}, \mathrm{J}=13.8 \mathrm{~Hz}), 3.51(\mathrm{~d}, 1 \mathrm{H}, \mathrm{J}=13.2 \mathrm{~Hz}), 3.22-3.16(\mathrm{~m}, 2 \mathrm{H}), 3.10(\mathrm{td}, 1 \mathrm{H}, \mathrm{J}=11.4,4.8$ $\mathrm{Hz}), 3.01-2.90(\mathrm{~m}, 3 \mathrm{H}), 2.84(\mathrm{~s}, 3 \mathrm{H}), 1.98-1.80(\mathrm{~m}, 2 \mathrm{H}) .{ }^{13} \mathrm{C}$ NMR $\left(150 \mathrm{MHz}, \mathrm{DMSO}-d_{6}\right) \delta 197.01,154.25,153.18$, $137.23,136.89$, 133.62, 130.72, 130.65, 130.54, 129.54, 128.61, 127.61, 127.20, 124.86, 124.77, 124.67, 124.23, 123.34, 
117.93, 117.61, 115.77, 66.02, 60.91, 60.02, 60.00, 59.38, 59.33, 46.97, 21.73. HMRS (ESI) for $\mathrm{C}_{28} \mathrm{H}_{28} \mathrm{NO}_{4}\left[\mathrm{M}_{-1}^{-}\right]^{+}$: Calcd m/z 456.2175, found: 456.2157 .

11. Previously, a water insoluble BINOL-based aldehyde showed fluorescence enhancement in the presence of Hcy but not with GSH, Cys and other amino acids in ethanol solution: Wang, Y.; Liu, S.; Ling, W.; Peng, Y. Chem. Commun. 2016, 52, 827-830.

12. Stevens, R.; Stevens, L.; Price, N. Biochemical Edu. 1983, 11, 70.

13. For a report on the $\mathrm{Zn}(\mathrm{II})$ complex of GSH, see: Krężel, A.; Bal, W. Bioinorganic Chem. 2004, 2, $293-305$.

14. Mei, J.; Leung, N.; Kwok, R.; Lam, J.; Tang, B. Chem. Rev. 2015, 115, 11718-11940. 


\section{Graphical Abstract}

Highly Selective Fluorescent Recognition of Glutathione by Using a Water Soluble Binaphthyl Aldehyde. Wei Chen, Xuedan $\mathrm{Wu}$ and Lin $\mathrm{Pu}^{*}$

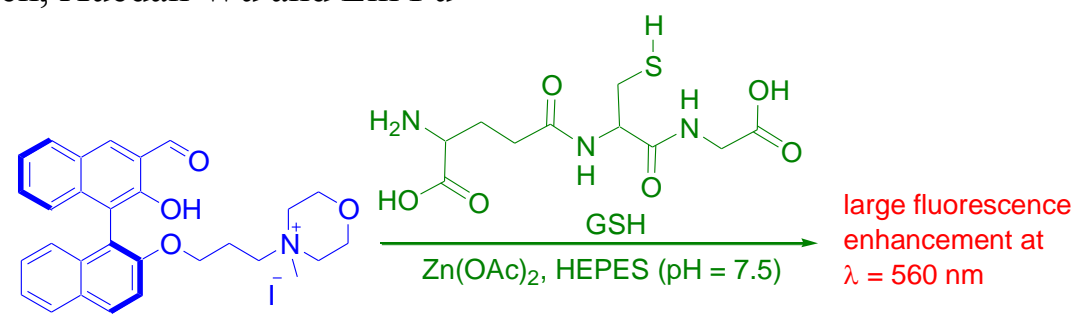

